\title{
MEMAHAMI PARIWISATA MELALUI PENDEKATAN GEOGRAFI MANUSIA
}

\author{
Oleh: \\ Hastuti \\ Jurusan Pendidikan Geografi FIS UNY \\ hastuti@uny.ac.id
}

\begin{abstract}
Abstrak
Indonesia memiliki keanekaragaman sosial budaya didukung kekayaan sumberdaya alam yang tersebar dari Sabang hingga Merauke maupun dari Miangas hingga Talaut, dapat dijadikan tumpuan pengembangan pariwisata yang diharapkan mampu memberikan kontribusi peningkatan penghidupan masyarakat. Indonesia gencar mempromosikan kekayaan alam, sosial, dan budaya berbagai wilayah sebagai tempat tujuan wisata yang menarik bagi wisatawan domestik dan wisatawan asing. Bali, Yogyakarta, Nusa Tenggara, serta beberapa wilayah di Sumatera dan Sulawesi potensial sebagai destinasi wisata potensial bertumpu pada sosial, budaya, dan alam. Pariwisata menarik perhatian pemerintah melalui paket-paket kebijakan seiring pariwisata juga mulai dikembangkan menjadi kajian keilmuan yang menarik pada berbagai disiplin di perguruan tinggi, tak terkecuali geografi juga mengkaji pariwisata sebagai salah satu subdisiplin dari geografi manusia. Geografi pariwisata mulai dikenalkan sebagai cabang disiplin geografi manusia (Kitchin dan Tate, 2000). Kajian pariwisata dikembangkan dengan pendekatan geografi manusia. Geografi manusia mengenalkan pendekatan humanistic, pospositivistic, radicalism, dan femisnism untuk mengkaji aspek antroposfer (Johnston dkk, 2000).
\end{abstract}

Kata kunci: Pariwisata, Geografi Manusia

\begin{abstract}
Indonesia has a socio-cultural diversity supported by abundant natural resources spred from Sabang to Merauke and from Miangas to Talaut. This can be used as a basis for developing a tourism that is expected to contribute to the improvement of the livelihood of the community. Indonesia has intensively promoted the natural, social, and cultural richness of different regions as an attractive tourist destination for domestic and foreign tourists. Bali, Yogyakarta, Nusa Tenggara, and some areas in Sumatra and Sulawesi are potential tourist destinations which offer social, cultural, and natural resources. Tourism has attracted the attention of the government through a set of policy along with the tourism advancement which begin to be developed into an interesting scientific study at various disciplines in universities, including geography which studies tourism as one of the sub-disciplines of human geography. Tourism geography began to be introduced as a branch of the human geography discipline (Kitchin and Tate, 2000). The study of tourism is developed utilizing human geography approaches. Human geography introduces humanistic, pospositivistic, radicalism, and femisnism approach to study the anthroposphere aspects (Johnston et al, 2000).
\end{abstract}

Keywords: Tourism, Human Geography 


\section{PENDAHULUAN}

Pariwisata mulai dikembangkan secara intensif sebagai sumber pendapatan banyak negara seiring makin berkurangnya penerimaan ekspor dari sektor migas dan mineral, tak terkecuali Indonesia. Indonesia diuntungkan sebagai negara yang memiliki kekayaan dan keanekaragaman sosial, budaya dan sumberdaya alam sebagai potensi strategis apabila dikembangkan pariwisata. Mendasarkan keyakinan tersebut Indonesia gencar untuk mempromosikan berbagai wilayah yang ada agar dapat dikembangkan sebagai tempat tujuan wisata.

Pengembangan pariwisata dengan melihat faktor internal dan faktor eksternal meliputi sosial, budaya, dan alam dengan analisis potensi wilayah lebih cermat agar seluruh wilayah dapat dikembangkan menjadi daerah tujuan wisata. Identifikasi dan kajian potensi wilayah penting dilakukan sebagai dasar pengembangan pariwisata. Pengembangan pariwisata berkelanjutan diharapkan dapat memberikan dampak positif kepada kesejahteraan pelaku pariwisata dan terjaganya sumberdaya pariwisata dengan menekan dampak negatif dari pariwisata. Pengembangan pariwisata di dunia ketiga terkait dengan peningkatan kedatangan turis dan perluasan pasar modal sehingga melalui pariwisata dapat menekan eksplotasi berlebihan terhadap sumberdaya (ZHAO Weibing dan LI Xingqun, 2006).

Keanekaragaman sumberdaya ini menjadi potensi pariwisata yang kemudian dikembangkan mulai dari wisata pegunungan, pantai, kuliner, atraksi budaya, peninggalan budaya, situs purbakala, dan masih banyak lagi potensi yang dapat dikembangkan sebagai objek pariwisata. Kegiatan pariwisata saat ini telah melibatkan wisatawan lintas bangsa disertai perubahan spasial, temporal, arus modal, informasi dan layanan global di sektor pariwisata, lebih jauh sektor pariwisata boleh jadi telah mengalahkan sektor industri dan ekonomi lain. Pariwisata terus dikembangkan berbasis sektor jasa, sehingga pariwisata dapat menjadi aktifitas yang menarik dengan melibatkan diversifikasi sosial, budaya, dan ekonomi melalui pengorganisasian dan pelestarian perbedaan wilayah, tradisi, dan budaya lokal ditengah derasnya pengaruh global. Kemampuan daya dukung migas yang semakin menurun dari waktu ke waktu mendorong munculnya gagasan untuk mengembangkan pariwisata menjadi prioritas sumber devisa masa depan.

Geografi manusia sebagai cabang geografi yang mengkaji aspek antroposfer menempatkan pariwisata sebagai sub-disiplin kajian, guna memahami aspek pariwisata dengan pendekatan geografi manusia. Guna mengkaji pariwisata secara utuh, geografi manusia mulai mengembangkan pendekatan geografi yang berbeda. Pendekatan geografi yang berbeda tersebut dikenalkan Jonhston et all (2000), sebagai aliran yang diikuti ahli geografi manusia. Geografi manusia sebagai cara untuk menggambarkan fenomena muka bumi secara sistematis, regional, deskriptif dan analitik agar mampu menjawab permasalahan muka bumi yang bervariasi sebagai rangkaian kerja geografi secara ideografik hingga nomotetik (Johnston et all, 2000). Geografi manusia mengusulkan adopsi penyelidikan geografis yang sensitif untuk menangkap kompleksitas kehidupan melalui kajian mendalam dalam studi kualitatif didukung oleh geograf feminis. 
Geografi manusia merupakan bagian dari geografi menjadi cabang ilmu tentu saja mengalami pasang surut. Sejak dikenal geografi pada masa idiografis melalui pengenalan geografi sebagai gambaran muka bumi yang memiliki karakteristik dan spesifik tanpa melihat mengapa dan bagaimana muka bumi memiliki variasi dari tempat ke tempat lain pada kurun waktu tertentu menandai dinamika geografi sebagai ilmu. Sesuai dengan perkembangan peradaban manusia geografi dikembangkan dengan paham sistematis, regional, deskriptif dan analitik untuk mampu menjawab permasalahan muka bumi yang bervariasi (Johnston et all, 2000).

Di Indonesia sejak tahun 1988, pasca pertemuan ahli geografi di Semarang, pendekatan yang popular diterapkan dalam kajian geografi adalah pendekatan keruangan, kelingkungan, dan kewilayahan, pendekatan ini merupakan pemikiran Petter Hagget dalam Modern Synthesis Geography. Mulai era 1990 an geografi manusia mulai mengalami kritik karena memiliki pendekatan yang dianggap lemah ketika dihadapkan dengan persoalan manusia di muka bumi, pendekatan dari Petter Haget cenderung mengabaikan filosofi humanistik yang digunakan untuk acuan pengembangan ilmu-ilmu sosial. Geografi manusia erat kaitannya dengan kajian tentang masyarakat pada wilayah tertentu, tentang sejarah yang mewarnai bentuk pemukiman, antropologi sosial, dan kegiatan ekonomi (Park dalam Smith, 2002).

Pendekatan humanistik memahami kenyataan seutuhnya secara benar dan jelas dengan dialog kritis, penalaran, dan pemikiran menyeluruh. Pendekatan ini menjadi landasan pemikiran untuk memperoleh kebenaran ilmiah dalam geografi manusia. Ketika geografi mulai bergeser dari paham deterministik, maka geografi mulai meletakkan manusia sebagai faktor utama dengan menawarkan paham posibilisme kemudian disusul paham probabilisme. Paham Posibilisme dan probabilisme memposisikan peran penting aspek antroposfer di muka bumi dengan mengkaji hubungan timbal balik antara alam dan manusia dalam struktur, pola dan proses pada tempat dan waktu tertentu di muka bumi kemudian menekankan kajian antroposentris. Pariwisata dalam kajian geografi manusia merupakan fenomena yang menarik terkait dengan mobilitas manusia, pemenuhan kebutuhan dan sumber pendapatan serta pemanfaatan sumberdaya sosial, budaya, dan alam yang menjadi potensi awal terjadinya pergerakan manusia secara vertikal dan horizontal.

\section{APA DAN BAGAIMANA PARIWISATA DALAM GEOGRAFI MANUSIA?}

Geografi manusia merupakan studi tentang manusia dalam perspektif geografi menekankan kapan, dimana, dan bagaimana manusia berevolusi, mengembangkan penghidupan dan persebaran manusia dari wilayah satu ke wilayah lain di muka bumi, analisis tentang bagaimana relasi manusia dengan lingkungan fisik, bagaimana manusia memanfaatkan sumber daya, manusia menyesuaikan kehidupan mereka dengan iklim yang berbeda dan budaya daerah yang berbeda (Gibson, 2009).

Secara eksplisit geografi manusia menurut Ratzel, Semple dan Paul Vidal de la Blache (Kitchin dan Tate, 2000). 
Ratzel

Human geography is the synthetic study of relationship between human societies and earth's surface". Human geography is the study of "the changing relationship between the unresting man and the unstable earth."

\section{Ellen C. Semple}

Dynamism in the relationship is the keyword in Semple's definition. "Conception resulting from a more synthetic knowledge of thephysical laws governing our earth and of the relations between the living beings which inhabit it".

Paul Vidal de la Blache

Human geography offers a new conception of the interrelationships between earth and human beings.

Fokus kajian geografi manusia adalah memahami kegiatan manusia di muka bumi dalam kaitannya dengan lingkungan kehidupan mereka dalam rangka mencari penghidupan mereka untuk mencapai kesejahteraan dan kebahagiaan. Kegiatan manusia semakin bervariasi bergantung pada dinamika penguasaan teknologi, ketersediaan sumberdaya, dan perilaku sosial budaya. Pariwisata merupakan salah satu kegiatan manusia sejak lama dan mulai berkembang pesat seiring dengan perkembangan teknologi transportasi dan informasi sehingga mendorong manusia melakukan perjalanan dari satu tempat ke tempat lain (Hall and Page, 2006). Pariwisata menjadi kajian penting dalam geografi manusia seiring dengan semakin pentingnya aspek pariwisata sebagai kegiatan manusia untuk memenuhi kebutuhan hidup mereka terkait kebutuhan sosial, budaya, dan ekonomi. Mengenai sub-disiplin kajian geografi pariwisata dapat dilihat pada Tabel 1.

Geografi pariwisata termasuk dalam sub disiplin kajian geografi ekonomi, hal tersebut dapat dipahami mengingat pariwisata saat ini bukan hanya untuk kepentingan sosial budaya tetapi telah dikelola secara ekonomi. Pariwisata dikembangkan sebagai sumber penghidupan karena dari sektor ini muncul lapangan kerja yang bervariasi yang mampu dijadikan tumpuan sumber pendapatan. Pariwisata menjadi fenomena kontemporer yang signifikan untuk dikaji secara terus menerus dan semakin banyak melibatkan kegiatan dan sektor lain. Pariwisata memberikan catatan penting melalui kajian pariwisata dengan tema kontemporer yang dapat dipelajari dalam geografi. Pariwisata termasuk interaksi antara modernitas dan mobilitas; globalisasi; pola baru produksi dan konsumsi; hubungan antara konsumsi dan identitas; dan akhirnya, keberlanjutan (Hall dan Page, 2006). 
Tabel 1. Pariwisata Dalam Geografi Manusia

\begin{tabular}{|c|c|c|}
\hline $\begin{array}{c}\text { Bidang Kajian } \\
\text { Geografi Manusia }\end{array}$ & Sub - Kajian & Kaitan Dengan Ilmu Sosial \\
\hline \multirow{8}{*}{ Geografi Sosial } & & Ilmu Sosial - Sosiologi \\
\hline & Geografi Perilaku & Psikologi \\
\hline & $\begin{array}{l}\text { Geografi Sosial } \\
\text { Kebahagiaan }\end{array}$ & Ekonomi Kesejahteraan \\
\hline & Geografi Rekreasi & Sosiologi \\
\hline & Geografi Budaya & Antropologi \\
\hline & Geografi Gender & Sosiologi, Antropologi, Studi Perempuan \\
\hline & Geografi Kesejarahan & Sejarah \\
\hline & Geografi Kesehatan & Epidemi \\
\hline Geografi Kota & - & Perencanaan dan Studi Kota \\
\hline \multirow{3}{*}{ Geografi Politik } & - & Ilmu Politik \\
\hline & Geografi Pemilihan & Psephology \\
\hline & Geografi Militer & Ilmu Militer \\
\hline Geografi Penduduk & - & Demografi \\
\hline $\begin{array}{l}\text { Geografi } \\
\text { Pemukiman }\end{array}$ & - & Perencanaan Kota Desa \\
\hline \multirow{7}{*}{ Geografi Ekonomi } & - & Ekonomi \\
\hline & $\begin{array}{l}\text { Geografi } \\
\text { Sumberdaya }\end{array}$ & Ekonomi Sumberdaya \\
\hline & Geografi Pertanian & Ilmu Pertanian \\
\hline & Geografi Industri & Ekonomi Industri \\
\hline & Geografi Pemasaran & Studi Bisnis dan Komersial \\
\hline & Geografi Pariwisata & Pengelolaan Tourisme and Travel \\
\hline & $\begin{array}{l}\text { Geografi } \\
\text { Perdagangan } \\
\text { Internasional }\end{array}$ & Perdagangan Internasional \\
\hline
\end{tabular}

Sumber: Fundamentals of Physical Geography (NCER T, 2006

\section{PENDEKATAN GEOGRAFI MANUSIA UNTUK KAJIAN PARIWISATA}

Pendekatan geografi manusia untuk kajian pariwisata dilakukan dengan kajian keilmuan mulai dari pertemuan ilmiah yang membahas pariwisata melalui seminar, penulisan eksemplar geografi pariwisata serta penelitian untuk kajian konteks realita yang sesungguhnya. Melalui peneliti diharapkan dapat menjelaskan secara rinci antara faktafakta yang diamati dengan konteks tempat terjadinya fakta tersebut. Pendekatan filosofi menjadi landasan pemikiran untuk memperoleh kebenaran ilmiah, tak terkecuali dalam memperoleh kebenaran dalam geografi. Geografi memiliki objek kajian manusia dan 
alam, positivism menjadi pendekatan yang populer dalam geografi pasca revolusi kuantitatif. Positivisme sebagai pendekatan filosofis berupaya menerapkan prinsip-prinsip ilmiah dan metode untuk kajian geografi memuat tentang prediksi dan penjelasan mengenai perilaku manusia secara kausal hanya dapat dilakukan ketika data diperoleh secara obyektif. Dengan statistik analisis dan pemodelan data, kajian geografi diharapkan mampu mengidentifikasi hukum-hukum universal yang akan menjelaskan pola, proses, dan struktur spasial, serta memprediksi masa depan maupun mengidentifikasi pola-pola tertentu secara konstruktif. Geografi kuantitatif mengacu pada kajian geografis positivistik.

Positivistik dalam geografi dianggap gagal menjelaskan proses sosial yang meliputi aktifitas manusia dimuka bumi menolak issue-issue politik, sosial, religi, kesenjangan antar kelompok masyarakat sebagai kenyataan yang ada pada kehidupan manusia yang dideskripsikan dan dianalogkan dalam model sederhana yang melahirkan generalisasi. Geografi positivistik memiliki kekurangan untuk menjelaskan tentang manusia. Manusia adalah makhluk yang kompleks yang tidak selalu berperilaku dengan cara yang mudah model. Geografi humanistik mengusulkan adopsi kajian geografis yang sensitive terhadap kompleksitas kehidupan orang melalui mendalam dalam studi kualitatif didukung oleh geograf feminis. Selama ini geografi sebagai ilmu spasial cenderung positivisme didukung rasionalitas maskulin.

A paradigmatic approach to geography begins in the 1950s when positivistic spatial science emerged to challenge and supersede the regional tradition in geography. In turn the positivist paradigm is understood to have been overturned in the 1970s by other approaches such as behaviourial geography, humanistic geography and radical approaches including Marxism and feminism. In the 1990s a paradigmatic perspective would understand poststructuralism as displacing these ways of thinking (Stuart Aitken and Gill Valentine, 2006)

Geografi dalam kajiannya memperhatikan tentang tema yang dijadikan pedoman untuk mengkaji fenomena pariwisata sebagai kegiatan manusia yang sudah ada sejak lama namun berkembang berkembang pada akhir millenium 20. Harvey (1986) mengemukakan ada lima tema dalam geografi yaitu: areal differentiation, landscape, manenvironment, spatial distribution, geometric, kelima tema tersebut menjadi kunci tema yang dijadikan pendekatan geografi manusia dalam membahas pariwisata (Hall dan Page, 2006). Haggett (1984), bahwa sebenarnya geografi dapat disebut sebagai ilmu tentang ekologi manusia yang menjelaskan hubungan antara lingkungan fisis dengan distribusi aktivitas manusia. Tekanan pada studi dengan tema manusia-lingkungan adalah terikat pada wilayah tertentu, sehingga mengarah kepada geografi regional. Tema ini nampaknya banyak disukai terutama dalam rangka studi pengembangan wilayah dengan sebutan lain analisis spasial/ keruangan. Perkembangan pendekatan geografi manusia dari waktu ke waktu dapat dilihat pada Tabel 2 berikut. 
Tabel 2. Periode dan Pendekatan Geografi Manusia

\begin{tabular}{|c|c|c|}
\hline Periode & Pendekatan & Cakupan Kajian \\
\hline Awal Kolonialisme & $\begin{array}{l}\text { Deskripsi dan } \\
\text { Eksplorasi }\end{array}$ & $\begin{array}{l}\text { Kepentingan Imperial dan perdagangan } \\
\text { mendorong penemuan dan eksplorasi } \\
\text { daerah baru. }\end{array}$ \\
\hline $\begin{array}{l}\text { Periode akhir } \\
\text { kolonialisme: }\end{array}$ & Analisis regional & $\begin{array}{l}\text { Deskripsi rumit dari semua aspek daerah } \\
\text { sehingga memahami bagian-bagian } \\
\text { dalam totalitas akan mengakibatkan } \\
\text { pemahaman keseluruhan. }\end{array}$ \\
\hline $\begin{array}{l}\text { Periode Perang } \\
\text { Dunia tahun } 1930 \\
\text { an }\end{array}$ & Defferensiasi Areal & $\begin{array}{l}\text { Fokus pada identifikasi keunikan wilayah } \\
\text { manapun dan memahami bagaimana dan } \\
\text { mengapa hal itu berbeda dengan yang } \\
\text { lain }\end{array}$ \\
\hline $\begin{array}{l}\text { Akhir tahun } 1950 \\
\text { hingga tahun } \\
1960 \text { an }\end{array}$ & Organisasi Spatial & $\begin{array}{l}\text { Ditandai dengan penggunaan komputer } \\
\text { dan alat statistik canggih untuk } \\
\text { memetakan dan menganalisis fenomena } \\
\text { manusia disebut revolusi kuantitatif. }\end{array}$ \\
\hline Tahun 1970 an & $\begin{array}{l}\text { Munculnya sekolah } \\
\text { sekolah dengan } \\
\text { kajian humistik, } \\
\text { radikalisme, dan } \\
\text { perubahan perilaku }\end{array}$ & $\begin{array}{l}\text { Ketidakpuasan dengan revolusi kuantitatif } \\
\text { dan cara manusiawi dalam melakukan } \\
\text { geografi menyebabkan munculnya tiga } \\
\text { sekolah baru pemikiran geografi manusia } \\
\text { pada } 1970 \text {-an. Geografi manusia dibuat } \\
\text { lebih relevan dengan realitas sosial-politik } \\
\text { dengan munculnya sekolah yang fokus } \\
\text { pada pemikiran humanistik, radikal, dan } \\
\text { perilaku }\end{array}$ \\
\hline Tahun 1990an & $\begin{array}{l}\text { Geografi Post- } \\
\text { modernisme }\end{array}$ & $\begin{array}{l}\text { Generalisasi dan penerapan teori } \\
\text { universal untuk menjelaskan kondisi } \\
\text { manusia. Pentingnya memahami setiap } \\
\text { konteks lokal dalam dirinya sendiri } \\
\text { ditekankan. }\end{array}$ \\
\hline
\end{tabular}

Sumber: Fundamentals of Physical Geography (NCER T, 2006).

Sebagaimana ditulis oleh Harvey (1986). Consider the following statement: Geography is concerned with the descriptive and explanation of the areal differentiation of the earth's surface. Konsep yang menjadi perhatian geografi, tentang bagaimana (how) dalam mempelajari fenomena, khususnya untuk operasionalisasi mengenai deskripsi dan eksplanasi.Tentang apa (what) yang harus dipelajari; hal ini memberi identifikasi wilayah (domain) objek dan peristiwa-peristiwa (events) bagaimana deskripsi dan explanasi harus 
dilakukan. Keys dan Mathew (2005) mengemukakan tentang lima tema geografi yakni location, place, human environment interactions, movement, dan regions. Fenomena pariwisata di muka bumi dikaji dengan perspektif geografi apabila dipahami dengan lima tema ini menjadi pedoman standard mulai dari perencanaan, pemecahan masalah hingga implikasi yang dapat disarankan oleh ahli ahli geografi untuk mengkaji pariwisata.

Tema lokasi (location) untuk menjawab pertanyaan dimana satu fenomena bagian muka bumi dikaji. Lokasi meliputi lokasi absolut yang dikaitkan dengan garis lintang dan garis bujur keberadaanya dimuka bumi cenderung tetap sepanjang waktu. Lokasi relatif cenderung berubah- ubah dalam periode waktu tertentu. Dalam studi geografi lokasi relatif mempunyai makna yang lebih penting dibandingkan dengan lokasi absolut. Pada lokasi relatif nilai-nilainya selalu diperbandingkan ataupun dihubungkan dengan dengan lokasi dari objek yang sejenis ataupun objek-objek lain di tempat berbeda. Hal ini berarti bahwa lokasi relatif mempunyai makna langsung dengan jarak. Jarak mempunyai tiga dimensi ukuran yaitu: pertama, jarak geometris dengan satuan ukuran kilometer, mil, yard, dan lain sebagainya. Kedua, jarak diukur dari segi dimensi waktu, misalnya, menit, jam, hari, minggu dan lain-lain. Ketiga, jarak diukur dari dimensi ongkos, yaitu biaya yang harus dikeluarkan untuk memindahkan barang per-kesatuan volume atau berat; demikian pula untuk memindahkan orang dari tempat ke tempat lainnya. Dengan adanya perbaikan saran dan prasarana transportasi, misalnya peningkatan kualitas jalan ataupun pembuatan jalan tembus serta munculnya alat-alat angkutan baru seperti, bus, truk, colt, serta alat angkutan lain, menimbulkan perubahan jarak dalam arti relatif dari lokasi-lokasi dihubungkan oleh jalur -jalur perhubungan itu.

Tema tempat (place) terkait antara lain dengan kajian ada apa, mengapa, dan bagaimana dengan tempat tersebut. Dikaitkan dengan karakteristik manusia dan fisik sehingga menimbulkan satu fenomena tertentu, fenomena yang berbeda antar tempat di muka bumi menjadi awal pariwisata yang dilakukan manusia. Karakteristik fisik termasuk didalamnya menenai pegunungan, dataran tinggi, sungai, tanah, batuan, pantai, belantara, dataran rendah disamping adanya karakteristik manusia. Karakteristik manusia meliputi ide dan gagasan yang memunculkan fenomena tertentu dikaitkan dengan karakteristik fisik didepan. Karakteristik manusia ini muncul sebagai fenomena perubahan lingkungan, munculnya bangunan / gedung- gedung, fasilitas jalan, pemenuhan kebutuhan papan, pangan, dan sandang serta kebutuhan lain. Sesuai dengan cipta rasa dan karsa manusia dengan kajian tempat ini muncul pengalaman, kemampuan manusia, untuk mensikapi karakteristik fisik sesuai dengan perkembangan peradapan umat manusia.

Tema human environmental interaction. dalam tema ini mengandung konsep manusia melakukan adaptasi terhadap lingkungan, manusia melakukan modifikasi terhadap lingkungan dan manusia bergantung pada lingkungan. Dalam tema human environmental interaction sejalan dengan faham geografi yang telah berkembang selama ini yakni deterministik, posibilistik dan probabilistik. Faham tentang kedudukan manusia terhadap alam yakni manusia dipengaruhi / ditentukan oleh alam dalam kehidupannya, manusia mempengaruhi/ mensiasati alam untuk kehidupannya, dan manusia dengan 
alam terdapat kesalingan sehingga ada ketergantungan, ada interaksi, ada interelasi antara manusia dengan alam dalam menciptakan keselarasan muka bumi.

Tema movement meliputi adanya perpindahan gagasan atau ide, perpindahan barang, dan perpindahan manusia. Dalam era global perpindahan gagasan, barang, dan manusia tanpa mengenal batas ruang dan waktu sehingga memunculkan persamaan dan perbedaan tentang fenomena muka bumi, dalam rangka aktualisasi manusia memenuhi kebutuhan pangan, papan, sandang, informasi.

Tema region merupakan unit dasar dalam kajian geografi yang saat ini sebagai pedoman dalam analisa geografi yang menjadi ciri pendekatan geografi sebagai ilmu. Untuk melihat wilayah dalam kajian fenomena muka bumi geografi mendasar pada formal regions, functional regions, dan vernacular regions. Wilayah berdasarkan pemerintahan, administratif, batas wilayah fisik mendasarkan pada kenampakan fisik, berdasarkan pada fungsi tertentu seperti pelayanan komunikasi, pelayanan ekonomi, pelayanan sosial serta berdasarkan persepsi yang diciptakan manusia seperti arah atau tujuan tertentu bagian barat, timur, sebelah selatan dll. Pariwisata dengan pendekatan geografi manusia merupakan salah satu aspek kajian geografi manusia sebagaimana dikemukakan Hall dan Page (2006) pada Tabel 3 berikut.

Tabel 3. Kajian Pariwisata Dengan Pendekatan Geografi Manusia

\begin{tabular}{|c|c|c|c|c|}
\hline D.G.Pearce(1979) & $\begin{array}{l}\text { R.V.Smith and } \\
\text { Mitchell (1990) }\end{array}$ & $\begin{array}{l}\text { Mitchell and } \\
\text { Murphy (1991) }\end{array}$ & Pearce (1995a) & $\begin{array}{l}\text { Hall and Lew } \\
\text { (1998) }\end{array}$ \\
\hline $\begin{array}{l}\text { Spatial patterns of } \\
\text { supply considerations }\end{array}$ & Spatial patterns & $\begin{array}{l}\text { Environmental } \\
\text { considerations }\end{array}$ & Tourism models & $\begin{array}{l}\text { Environmental } \\
\text { considerations }\end{array}$ \\
\hline $\begin{array}{l}\text { Spatial patterns of } \\
\text { demand }\end{array}$ & $\begin{array}{l}\text { Tourism in } \\
\text { developing } \\
\text { countries }\end{array}$ & $\begin{array}{l}\text { Regional } \\
\text { considerations }\end{array}$ & $\begin{array}{l}\text { Demand for } \\
\text { tourist travel }\end{array}$ & $\begin{array}{l}\text { Regional } \\
\text { considerations }\end{array}$ \\
\hline Geography of resorts & $\begin{array}{l}\text { Evolution of } \\
\text { tourism }\end{array}$ & $\begin{array}{l}\text { Spatial } \\
\text { considerations }\end{array}$ & $\begin{array}{l}\text { International } \\
\text { tourism patterns }\end{array}$ & $\begin{array}{l}\text { Spatial } \\
\text { considerations }\end{array}$ \\
\hline $\begin{array}{l}\text { Tourist movements and } \\
\text { flows }\end{array}$ & Impacts of tourism & $\begin{array}{l}\text { Evolutionary } \\
\text { considerations }\end{array}$ & $\begin{array}{l}\text { Intra-national } \\
\text { travel patterns }\end{array}$ & $\begin{array}{l}\text { Evolutionary } \\
\text { considerations }\end{array}$ \\
\hline Impact of tourism & $\begin{array}{l}\text { Tourism research } \\
\text { methods }\end{array}$ & & $\begin{array}{l}\text { Domestic tourist } \\
\text { flows }\end{array}$ & Tourism planning \\
\hline \multirow[t]{6}{*}{ Models of tourist space } & $\begin{array}{l}\text { Planning and } \\
\text { development }\end{array}$ & & $\begin{array}{l}\text { Spatial variations } \\
\text { in tourism }\end{array}$ & Urban tourism \\
\hline & Coastal tourism & & $\begin{array}{l}\text { National and } \\
\text { regional } \\
\text { structures of } \\
\text { tourism }\end{array}$ & $\begin{array}{l}\text { Modernisation and } \\
\text { development }\end{array}$ \\
\hline & $\begin{array}{l}\text { Tourism } \\
\text { accommodation }\end{array}$ & & & \\
\hline & Resort cycles & & $\begin{array}{l}\text { Spatial structure } \\
\text { of tourism on } \\
\text { islands }\end{array}$ & Gender and identity \\
\hline & Tourism concepts & & Coastal resorts & $\begin{array}{l}\text { Place marketing } \\
\text { and promotion }\end{array}$ \\
\hline & $\begin{array}{l}\text { Tourism } \\
\text { destinations }\end{array}$ & & Urban areas & $\begin{array}{l}\text { Globalisation and } \\
\text { economic and } \\
\text { cultural change } \\
\text { Sustainable } \\
\text { development }\end{array}$ \\
\hline
\end{tabular}

Sumber: C.Michael Hall and Stephen J.Page, 2006

Tema- tema geografi dapat dijadikan kerangka kerja dalam setiap kajian fenomena muka bumi dengan bingkai geografi. Dinamika perubahan tema- tema ini akan terus berkembang sesuai dengan perkembangan ilmu dan semakin kompleksnya permasalahan tentang fenomena geografi. Geografi manusia merupakan cabang geografi 
memiliki obyek material yang menekankan tentang perilaku dan aktiofitas manusia di muka bumi. Tantangan yang diperlukan adalah meningkatkan kinerja para tokoh dalam institusi yang kondusif agar geografi manusia dapat berperan untuk menjawab permasalahan terkait dengan apa, dimana, kenapa, dan bagaimana relasi manusia dengan alam dengan fokus kajian tentang manusia dalam ruang dan tempat di muka bumi masa lalu, masa sekarang, dan masa depan.

Mulai awal tahun 1980 an pariwisata menjadi kajian geografi manusia yang menerapkan pendekatan geografi manusia untuk menjawab problematik pariwisata dengan memperhatikan pola spatial, pergerakan wisatawan dampak pariwisata serta mencari model spatial untuk kegiatan pariwisata. Tahun ke tahun aspek kajian pariwisata dengan pendekatan geografi manusia semakin berkembang karena persoalan pariwisata makin kompleks seiring dengan semakin kompleksnya persoalan pariwisata yang banyak melibatkan sektor lain baik pada tingkat lokal, regional, hingga global. Pariwisata pada awal perkembangan sekedar bagaimana manusia melakukan perjalanan untuk mencari fenomena berbeda, saat ini pariwisata sudah berkembang menjadi industri pariwisata yang bersifat individu dan massal mulai tingkat lokal hingga global.

Kegiatan pariwisata secara global melibatkan wisatawan lintas bangsa disertai perubahan spasial dan temporal, arus modal, informasi dan layanan global di sektor pariwisata. Pariwisata boleh jadi mengalahkan sektor industri dan ekonomi lain di masa depan dan pariwisata terus berkembang berbasis sektor jasa. Pariwisata menjadi aktifitas yang menarik yang melibatkan kekuatan global sebagai hasil komunikasi tindakan lokal melalui pengorganisasian dan pelestarian perbedaan wilayah, tradisi, dan budaya asli. Pariwisata akan dapat berkembang apabila terdapat perbedaan fenomena di muka bumi karena prinsip pariwisata adalah melihat hal berbeda di tempat tujuan. Meskipun globalisasi pariwisata terus berlangsung namun dukungan kondisi lokal menjadi aspek penting dalam pengembangan pariwisata (Kevin Fox Gotham, 2005). Geografi sebagai studi tentang perbedaan dan persamaan fenomena muka bumi, konsep senafas dengan konsep dasar pariwisata. Pariwisata memiliki makna adanya pergerakan manusia dari satu tempat ke tempat lain untuk melihat hal berbeda serta merasakan suasana yang berbeda dari kegiatan dan kehidupan sehari-hari yang dilakukan. Konsep tersebut yang menjadi awal berlangsungnya pariwisata hingga saat ini ditunjang dengan semakin berkembangnya teknologi informasi, komunikasi, dan transportasi menjadikan pariwisata semakin banyak melibatkan pergerakan atau mobilitas manusia.

\section{PENUTUP}

Keanekaragaman sumberdaya menjadi potensi pariwisata, saat ini pariwisata telah melibatkan wisatawan lintas bangsa, di masa depan pariwisata dapat mengalahkan sektor industri dan ekonomi lain. Pariwisata terus dikembangkan berbasis sektor jasa, sehingga pariwisata dapat menjadi aktifitas yang menarik dengan melibatkan diversifikasi sosial budaya dan ekonomi melalui pengorganisasian dan pelestarian perbedaan wilayah, tradisi, dan budaya lokal ditengah derasnya pengaruh global. Pariwisata merupakan fenomena yang menarik terkait dengan mobilitas manusia, pemenuhan kebutuhan dan 
sumber pendapatan serta pemanfaatan sumberdaya sosial, budaya, dan alam yang menjadi potensi awal terjadinya pergerakan manusia secara vertikal dan horizontal.

Geografi manusia sebagai cabang geografi yang mengkaji aspek antroposfer menempatkan pariwisata sebagai sub-disiplin kajian, guna memahami aspek pariwisata dengan pendekatan geografi manusia. Mulai era 1990 an geografi manusia mulai mengalami kritik karena memiliki pendekatan yang dianggap lemah ketika dihadapkan dengan persoalan manusia di muka bumi, karena pendekatan dari Petter Haget cenderung mengabaikan filosofi humanistik. Sejak itu pariwisata mulai dikembangkan dalam kajian geografi manusia dengan pendekatan humanistic, pospositivistic, radicalism, dan femisnism. Pariwisata dikaji melalui berbagai forum ilmiah, bahwa memahami pariwisata dalam kajian geografi manusia menjadi menarik sehingga riset, eksemplar, seminar, subject matter dan diskusi ilmiah tentang pariwisata dari perspektif geografi manusia berkembang pesat (Hall dan page, 2006).

\section{UCAPAN TERIMA KASIH}

Pada kesempatan ini penulis mengucapkan terima kasih kepada berbagai pihak yang telah membantu dalam penyusunan artikel ini. Penulis juga mengucapkan terima kasih kepada redaksi sehingga tulisan ini dapat diterbitkan pada jurnal geomedia volume 15 Nomer 1 Mei 2017.

\section{DAFTAR PUSTAKA}

de Blij, H.J. dan Murphy, Alexander B, 2003, Human Geography Culture, Society, and Space, John Wiley \& Son, Inc, Wiley

Gibson, Chris, 2009. Locating geographies of tourism. Human Geography, University of Wollongong, NSW, Australia. Elsevier Inc.

2010. Geographies of tourism: (un)ethical encounters. Progress in Human Geography 34(4) (2010) pp. 521-527.

Hagerstrand, 1999, Diorama, Path, and Project dalam Agnew, John, Livingstone, David N, dan Rogers, Alisdair, 1999, Human Geography An Essential Anthology, Blackwell Publish, Oxford

Hagget, Peter, 1984. Geography: A Modern Synthesis. Harper and Row., New York.

Hall. C.Michael and Page. Stephen J., 2006. The Geography of Tourism And Recreation. Environment, place and space Routledge, New York USA Third edition Hammond C dan Whynne, 1989. Element of Human Geography, Oxford University Press Harvey, D, 1986. Explanation in Geography. Edward Arnold: Baltimore, Maryland.

Johnston, R. J. 2004a: Institutions and disciplinary fortunes: two moments in the history of UK geography in the $1960 \mathrm{~s}-\mathrm{I}$ : geography in the 'plateglass universities'. Progress in Human Geography, 28, 57-78.

Kitchin Rob and Nicholas, J. Tate. (2000). Conducting Research in Human Geography:Theory, Methodology and Practice.Addison Wesley Longman, Singapore (Pte) Ltd., Singapore.

Knox, PL dan Marston SA, 2004, Human Geography Places and Regions in Global Context, Pearson Edc, New Jersey

Macleod, Donald V.L, 2004, Tourism, Globalization, and Cultural Change: An Island Community Perspective, British Library Cataloguing in Publication Data 
Mc Dowell, Linda dan Massey, Doreen, 1996, A Woman's place?. dalam Human Geography An Essential Anthology, Agnew

NCER T, 2006. Fundamentals of Physical Geography

Nystuen, John D, 1999, Identification of Some Fundamental Spatial Concept dalam Agnew, John, Livingstone, David N, dan Rogers, Alisdair, 1999, Human Geography An Essential Anthology, Blackwell Publish, Oxford

Pred, Allan (ed.), 1981, Space and Time in Geography - Essays Dedicated to Torsten Hägerstrand; CWK Gleerup, Lund

Sauer, Carl, 1999, The Morphology of Landscape dalam Agnew, John, Livingstone, David N, dan Rogers, Alisdair, 1999, Human Geography An Essential Anthology, Blackwell Publish, Oxford

Smith, N. 2000: Socializing culture, radicalising the social. Social and Cultural Geography $1(1), 25-28$.

Stuart Aitken and Gill Valentine, 2006, Ways of Knowing and Ways of doing geographic research, dalam Approaches to Human Geography, SAGE Publish London.

Viles, Heather, 2005, A Devided Discipline?, dalam Castree, N; Rogers,A; dan Sherman, D, Questioning Geography Fundamental debate, 2005, Blackwell Publish, USA

Wilson, Helen F. 2006. On geography and encounter: Bodies, borders, and difference. Progress in Human Geography 1-21 a The Author(s) 2016. Reprints and permission: sagepub.co.uk/journalsPermissions.nav

Zhoa Weibing dan Li Xingqun, 2006, Globalization of Tourism and Third World Tourism Development A Political Economy Perspective, Chinese Geographical Science 2006 16(3) 203-210 